Demiryolu Mühendisliği

Temmuz 2021

Say1:14, Sayfa: 180-188

Araştırma Makalesi

http://dergipark.org.tt

e-ISSN: 2687-2463, ISSN: 2149-1607

Railway Engineering

July 2021

Issue:14, Page: 180-188

Research Article

\title{
Hidrojenle Çalışan Demiryolu Araçlarında Kullanılan Hidrojen Tüplerinin Yüksek Hızlı Darbeye Karşı Dirençlerinin Sonlu Elemanlar Yöntemi ile İncelenmesi
}

\author{
Nihat AKKUŞ@, Abdülkadir ÜNAL*®), Garip GENÇ® \\ Marmara Üniversitesi, Fen Bilimleri Enstitüsü, Mekatronik Mühendisliği Bölümü, İstanbul Türkiye \\ *abdulkadir.unal@turasas.gov.tr
}

(Alınış/Received: 29.05.2021, Kabul/Accepted: 29.06.2021, Yayımlama/Published: 31.07.2021)

\begin{abstract}
Öz: Hidrojen enerjisi dizel tren setlerinin yol açtığı hava kirliliği, gürültü kirliliği gibi dezavantajları ortadan kaldırdığı gibi elektrikli tren setlerinin ihtiyaç duyduğu pahalı elektrifikasyon alt yapısı ve görüntü kirliliğinin de olumsuz etkilerini ortadan kaldırmaktadır. Bu olumlu özelliklere karşı hidrojenin yüksek basınç altında depolanması gerekmektedir. Bu çalışmada hidrojenin alternatif bir enerji kaynağı olarak demiryolu araçlarında kullanılması ve hidrojen tüplerinin yüksek hızlı darbeye karşı dirençleri sonlu elemanlar yöntemi ile incelenmiştir. Bu amaçla yüksek iç basıncı olan ve olmayan Karbon Fiberle Güçlendirilmiş Plastik (CFRP) kompozit tüp üzerine darbe yüklemesinin etkisi FEM simülasyonu ile araştırılmıştır. Alüminyum silindirli ve karbon fiber ile sarılmış kompozit tüp 3 boyutlu model kullanılarak simüle edilmiştir. MARC-Mentat ticari kodu, hesaplama aracı olarak seçilmiştir. Silindirin geometrisi, Mentat ön-son arayüz yazılımı kullanılarak oluşturulmuştur. Alüminyum 6061T astar ve TORAY T 700SC + Epoksi kompozit katmanların malzeme özellikleri sırasıyla izotropik ve ortografik olarak simülasyonlara dâhil edilmiştir. Tüpün kubbe bölgesi simülasyonlara dâhil edilmemiş̧ir. Simülasyonun modeli, başka bir araştırmacı tarafından yapılan gerçek deney dikkate alınarak oluşturulmuştur. Simülasyonların sonuçları, çarpma tertibatı hasarı altındaki bazı bölgelerin, genellikle inanılan gerilim deformasyonundan ziyade sıkıştırma gerilmelerine maruz kalacağını göstermektedir.
\end{abstract}

Anahtar kelimeler: Hidrojen, Hidrojen tüpleri, Kompozit, FEA

\section{Investigation of High Speed Impact Resistance of Hydrogen Tubes Used in Hydrogen- Powered Railway Vehicles by Finite Element Method}

\begin{abstract}
Hydrogen energy eliminates the disadvantages such as air pollution and noise pollution caused by diesel train sets, as well as the negative effects such as expensive electrification infrastructure and visual pollution required by electric train sets. Against these positive properties, hydrogen must be stored under high pressure. In this study, the use of hydrogen as an alternative energy source in railway vehicles and the high-speed impact resistance of hydrogen tubes were investigated by the finite element method. The effect of impact loading on Carbon Fiber Reinforced Plastic (CFRP) composite tubes without and with high internal pressure has been investigated by FEM simulation for this purpose. The composite tube which has an Aluminum cylinder and wound by carbon fiber was simulated by using the 3-D model. MARC-Mentat commercial code has been selected as a computational tool. The geometry of the cylinder has been generated using Mentat pre-post interface software. The material properties of the Aluminum 6061T liner and TORAY T-700SC + Epoxy composite layers have been included in the simulations as isotropic and orthographic, respectively. The dome region of the vessel has not been included in the simulations. The model of the simulation has been created by considering the real experiment which has been conducted by another researcher. The results of the simulations show that some zones under the impactor damage would face compressions stresses rather than tensional deformation, which is generally believed.
\end{abstract}

Keywords: Hydrogen, Hydrogen tubes, Composite, FEA

Atıf için/Cite as: N. Akkuş, A. Ünal, G. Genç, "Hidrojenle çalışan demiryolu araçlarında kullanılan hidrojen tüplerinin yüksek hızlı darbeye karşı dirençlerinin sonlu elemanlar yöntemi ile incelenmesi," Demiryolu Mühendisliği, no. 14, pp. 180-188, July. 2021. doi: 10.47072/demiryolu.944604 


\section{Giriş}

Hidrojen enerjisi, çevresel emisyonlar, sürdürülebilirlik ve enerji güvenliği konularında yardımcı olabilen, yirmi birinci yüzyıl için potansiyel bir enerji çözümünün temel unsurlarından biri olarak kabul edilmektedir [1]. Bu yüzden motorlu taşıtlarda hidrojenin kullanılması yaygın olarak araştırılmaktadır [2].

Dünyada birçok hidrojen yakıtlı otomobil ve otobüs çalışmakta ve hidrojen yakıt ikmali ağ 1 istikrarlı bir şekilde büyümektedir. Ayrıca demiryolu ortamında, hidrojen, elektrifikasyon altyapısının ekonomik olarak mümkün olmadığı yerlerde dizelin yerini alabilen uygun bir enerji taşıyıcısı olarak görülmektedir [3]. Hidrojen yakıtlı trenler dizel tren setlerinin meydana getirdiği gürültü ve hava kirliliğini ortadan kaldırdığ 1 gibi elektrikli tren setleri için gerekli olan pahalı elektrifikasyon altyapısı ve görüntü kirliliğini de ortadan kaldırmaktadır.

Demiryolları için ilk hidrojenle çalışan lokomotif 2007-2009 yılları arasında Kuzey Amerika'da geliştirilmiştir. Ardından 2010-2013 yılları arasında İspanya'da prototip hidrojen yakıtlı tramvay geliştirilmiştir. Başka bir deneysel çalışmada, bir İngiliz araştırma grubu sayısal modeller geliştirmiş ve karşılaştırma ölçütü olarak tipik bir gezi ve tren sistemi kullanmıştır [4]. 2016 yılında Berlin'deki Inno Trans fuarında sunulan ve Alstom tarafından üretilen Corodia iLint 2018 yılında Almanya'da ticari olarak faaliyete girmiş ve ticari olarak işletilen ilk tren olduğu gibi günümüzde de hidrojen ile çalı̧̧an tek tren seti olma özelliğini sürdürmektedir.

Hem araçta hem de genel altyapıda güvenli hidrojen kullanımı, bu teknolojinin sosyal olarak kabul edilebilirliğinin önemli bir sorunudur [5]. Hidrojen havadan çok daha hafif olduğu için, hızlı bir şekilde dağılır. Bu yüzden yakıt tanklarının demiryolu araçlarının çatılarına yerleştirmek daha güvenli olacaktır. Tren setlerine uygulanabilecek örnek bir ekipman yerleşimi Şekil 1'de verilmiștir.

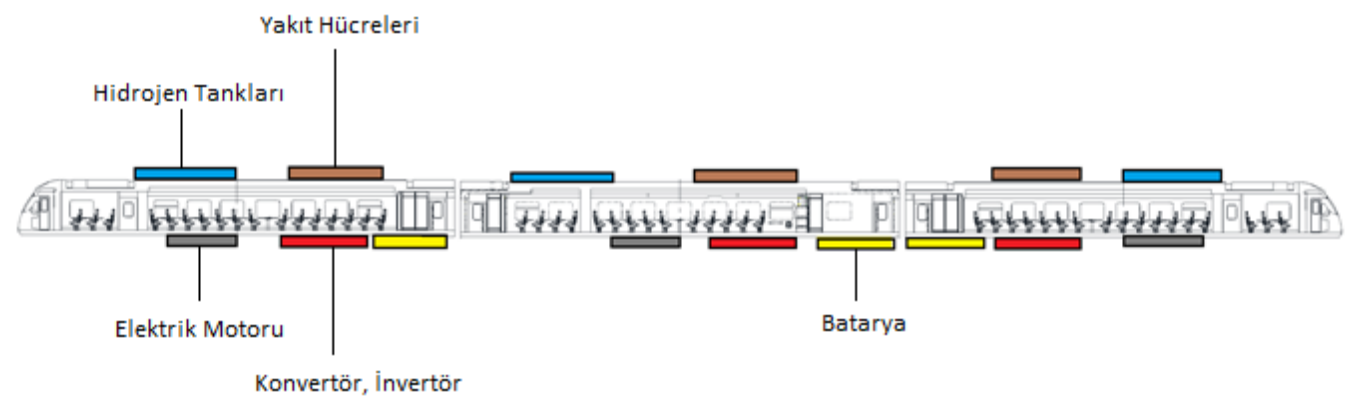

Şekil 1. Hidrojen yakıtlı tren setlerinde genel ekipman yerleşimi

Hidrojen gaz olarak üretilir ve bu nedenle gaz halinde depolanması bariz bir seçimdir. Bununla birlikte atmosfer basıncinda hidrojenin düşük hacimsel yoğunluğu, kabul edilebilir tank boyutlarına ulaşmak için sıkıştırılmalıdır [6]. Basınç son derece yüksektir ve son derece sağlam bir tank gerektirir. $\mathrm{Bu}$, tankın şeklini bir silindire sınırlar ve araç mimarisine entegrasyonunu zorlaştırır. Sıkıştırılmış gazın kinetiği idealdir ve yakıt akışı neredeyse sınırsız bir şekilde artabilir veya azalabilir. Güvenlik açısından bakıldığında, karbon fiber gibi tipik malzemeler toksik veya çevreye zararlı değildir [7].

Hidrojenin sıkıştırılması neticesinde meydana gelen yüksek basınç her zaman bir riski temsil eder. Bu nedenle tankların yüksek hızlı darbeye karşı dirençli olmaları gerekmektedir. Polimer matris kompozitler, yüksek özgül sertlik ve yüksek özgül mukavemet ile karakterize edilmelerine rağmen, darbe yüklemesine karşı hassastırlar. Bu tür malzemelerin yapısal uygulamalarda etkin kullanım için yüksek hız etkisi altındaki davranışları açıkça anlaşılmalıdır. 
Naik vd. [8] iki boyutlu dokuma kumaşın balistik darbe davranışı üzerine araştırmalarını sunmuştur. Tan vd. [9], kumaşın ortotropik özelliklerini, ipliklerin viskoelastik yapısını, ipliklerin kıvrılmasını, iplikler arasındaki kayma temasını ve viskoelastik çubuk elemanlarının bir montajını kullanarak iplik kopmasını yansıtan bir dokuma kumaşın FE modelini sunmuştur. Duan vd. [10], sert bir kürenin dörtkenarı boyunca sıkıca tutturulmuş kare bir kumaş panel üzerindeki balistik etkisi sırasında sürtünmenin etkisini incelemek için bir sonlu eleman analizi sunmuş ve mermikumaş sürtünmesi ve iplik-iplik sürtünmesini incelemiştir. Fawaz vd. [11], Florences modelini ve yeni bir hibrit çözme tekniğini kullanarak iki bileşenli zırhların optimum tasarımı için etkili bir metodoloji sunmuştur. Übeyli vd. [12], çeliğin 7,62 mm zırh delici mermilere karşı balistik performansını sunmuştur. Lopresto vd. [13], davranışları genel kuvvet-yer değiştirme eğrisi, ilk göçme yükü, penetrasyon, girinti ve hasar kapsamına göre incelenen çeşitli kalınlıklarda dikişli karbon fiber takviyeli plastik laminantlar üzerinde düşük hızlı darbe testlerinin gerçekleştirilmesini araştırmıştır. Duan vd. [14], sert bir sağ dairesel silindirin düz dokuma kevlar kumaştan kare bir yama üzerine enine etkisini simüle etmek için LS-DYNA kullanarak 3-D sonlu elemanlar analiz modelini incelemiştir. Mamalis vd. [15], simülasyon çalışmalarında LS-DYNA 3D açık sonlu eleman kodunun, statik eksenel sıkıştırma ve darbe testine tabi tutulmuş kare karbon fiber takviyeli plastik tüplerin sıkıştırma özelliklerini ve kırılma yanıtını araştırmıştır. Abdullah vd. [16], bir dizi polipropilen bazlı fiber-metal laminant (FML) yapısının yüksek hızlı darbe tepkisini araştırmıştır. Caprino vd. [17], farklı kalınlıklarda dört adet dikişli grafit / epoksi laminatın yüksek hızlı darbe testlerini incelemiştir. İki farklı hızda $(65$ ve $129 \mathrm{~m} / \mathrm{s})$ gerçekleştirilen testlerde mermi olarak 12,7 ve $20 \mathrm{~mm}$ çapında iki çelik küre kullanılmıştır.

Yukarıda görüldüğü gibi, çalışmaların çoğu, her ikisi de gerçek durumlardan uzak olan düşük hızlı balistik etki ve yarı statik yükleme üzerine yoğunlaşmıştır ve hasar, silindirlerin yüksek hızlı darbe yüklemesi altında meydana gelmektedir. Yüksek hızda yapılan bazı çalışmalarda silindir yerine laminantlar kullanılmıştır. Bu çalışmada, $\mathrm{Al}+\mathrm{CFRP}$ kompozit tüpte çarpma hızının düşük hızdan yüksek hızlı yüklemeye kadar değişebileceği bir FE modeli önerilmiştir. FE modeli, çarpma tertibatının boru üzerinde bir girinti yaptıktan sonra meydana gelen Al ve kompozit deformasyon açısından deneyle karşılaştırılmıştır. $\mathrm{Bu}, \mathrm{FE}$ modelinin güvenilirliğini anlamak için önemlidir.

\section{Metot}

Darbe yüklemesi altındaki Al + FRP kompozit tüp, MSC Marc Mentat sonlu eleman simülasyon programı $[18,19]$ kullanılarak modellenmiştir. Yazılım platformu, $2 \mathrm{GHz}$ hızında, iki işlemcili ve Windows XP işletim sistemli bir masaüstü bilgisayardır. Tüpün boyutu ve malzeme özellikleri, Takekusa ve arkadaşları tarafindan yapılan önceki bir çalışmadan elde edilmiştir [20]. Kompozit tüpün boyutları ve şematik çizimi Şekil 2'de verilmiştir.
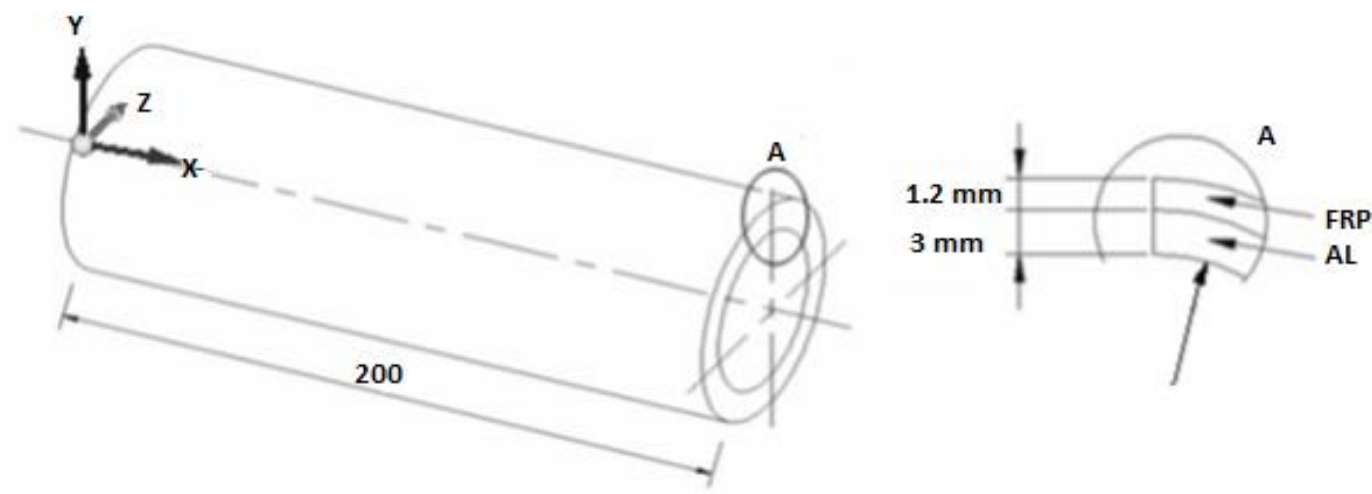

Şekil 2. Kompozit borunun şematik çizimi 
Karbon fiber ve alüminyum tüpün malzeme özellikleri Tablo 1'de verilmiştir. Alüminyum malzeme izotropik, karbon fiber + epoksi kompozit ortotropik malzeme olarak kabul edilmiştir. Geometri, 3960 katı eleman 6919 düğüm ile oluşturulmuştur. Marc eleman kitaplığında 3 boyutlu bir katı eleman sayısı-7 seçilmiştir. Elyaf oryantasyonu, kalınlık dağılımı, istifleme sırası ve katman sayısı kompozit yapıyı tanımlamak için kullanılan parametrelerdir.

Tüpün bir ucundaki düğümler $\mathrm{X}$ ekseni boyunca sabitlenmiştir ve tüpün diğer ucundaki düğümler $X$ ekseni deformasyonları boyunca serbest bırakılmıştır. Tüpün her iki ucunda bulunan tüm düğümler $\mathrm{Y}$ ve $\mathrm{Z}$ yönünde sabitlenerek sınır koşullarının deneylerdekine benzer olması sağlanmıştır. Sınır koşulları ve çarpma tertibatını simüle eden sert küre Şekil 2 (a)'da gösterilmektedir. Simülasyonda darbe yüklemesinden sonra deforme olan tüp şekli de Şekil 3'te verilmiştir.

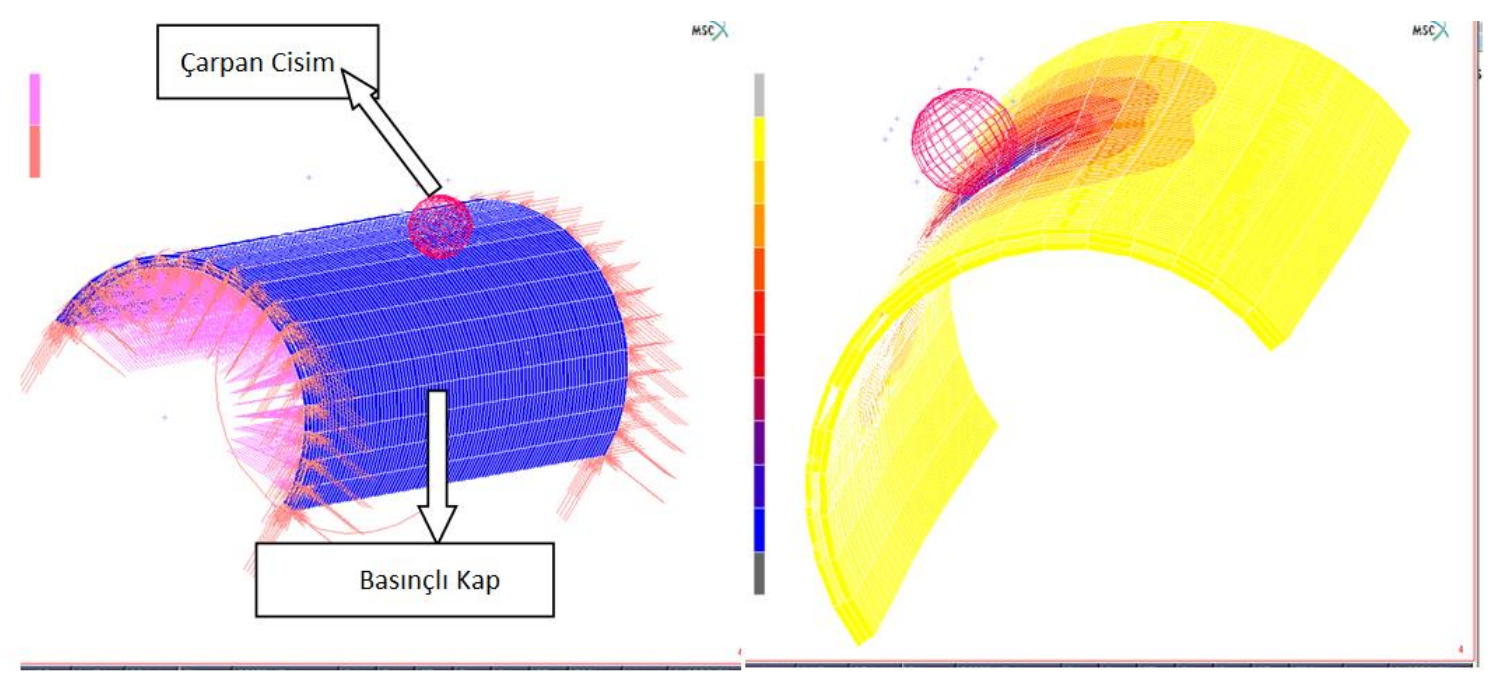

Şekil 3. (a) Sınır koşulları (b) FEM simülasyonunda deforme olmuş şekil

Tablo 1. Alüminyum astar ve fiber malzemenin malzeme özellikleri

\begin{tabular}{ccccc}
\hline & $\begin{array}{c}\text { Çekme Modülü } \\
{[\mathrm{GPa}]}\end{array}$ & $\begin{array}{c}\text { Akma Dayanımı } \\
{[\mathrm{MPa}]}\end{array}$ & $\begin{array}{c}\text { Çekme Dayanımı } \\
{[\mathrm{MPa}]}\end{array}$ & Yüzde Uzama \\
& & & & \\
\hline A6061-O & 68,6 & $<110$ & $<145$ & $>16$ \\
T-700-24K & 230 & - & 4900 & 2,1 \\
\hline
\end{tabular}

Alüminyum tüpün dış çapı $100 \mathrm{~mm}$, kalınlığı $3 \mathrm{~mm}$, karbon fiber takviyeli polimer (CFRP) kalınlığ 1,2 mm ve tüp uzunluğu 200 mm'dir. Alüminyum boruyu karbon fiber kompozit ile kaplamak için tek başına çember sarımı kullanılmıştır. Sarmal sargı gibi başka bir sargı kullanılmamıştır. FE modelinin güvenilirliğini doğrulamak için referans [20]'de açıklanan deneysel parametreler FEM simülasyonuna girilmiştir. Kompozit ve alüminyum tüp üzerinde aynı deformasyon derinliği elde edilmiştir. Bu girinti, aynı referansta $\mathrm{Al}+\mathrm{CFRP}$ kompozit silindirler üzerinde gerçekleştirilen tek sıçrama darbe testlerinden kaynaklanmıştır. Şekil 4, deformasyon derinliği açısından simülasyonun deneyle karşılaştırmasını göstermektedir. Yüksek çarpma hızı ve kısa test süresi nedeniyle darbe testi sırasında farklı veriler elde etmek çok zordur. Yüksek hızlı testler, deneysel verileri elde etmek için daha karmaşık ve pahalı ekipmanlara da ihtiyaç duyar. Bu nedenle FE modelinin güvenilirliği anlaşıldıktan sonra kompozit tüpün gerilme ve gerinim varyasyonunu görmek için simülasyon yapmak çok faydalıdır. 

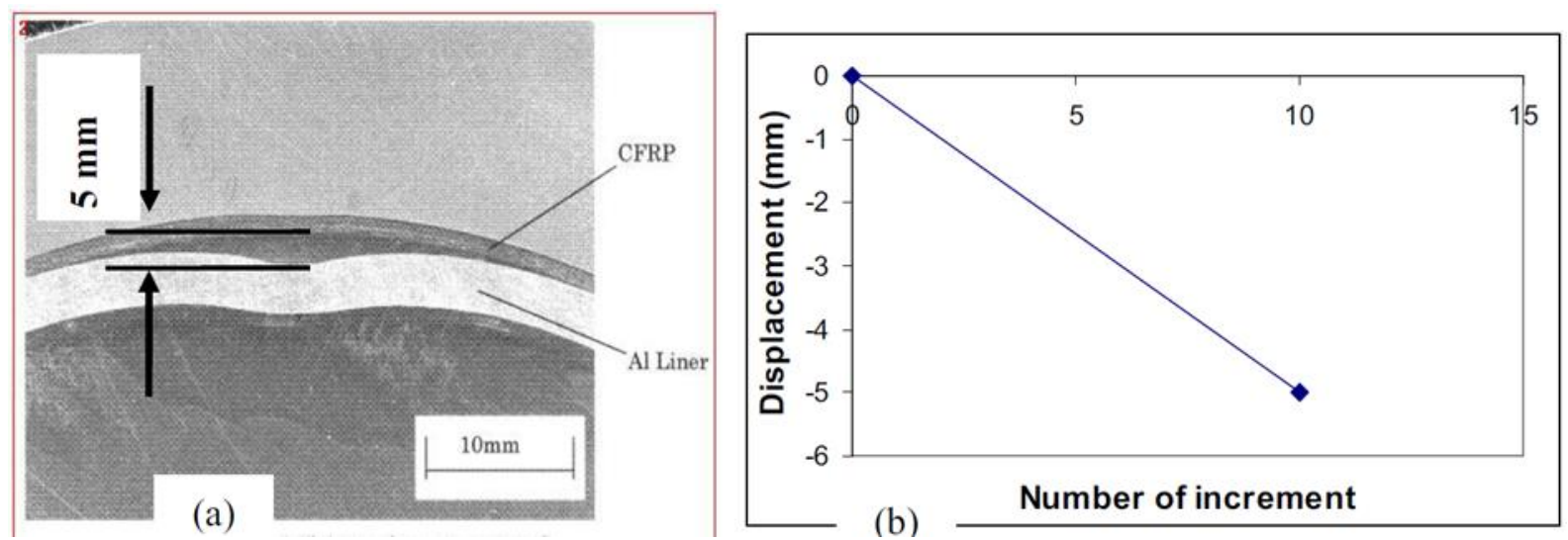

Şekil 4. Girinti derinliği açısından deneylerin simülasyonla karşılaştırılması. (a) çarpma tertibatı kompozit tüpe [20] çarptıktan sonra deforme olan şekil (b) simülasyondaki yer değiştirme ve adım sayısı

\section{Bulgular}

Yüzey hasarının, bir (FW) gaz silindirine sarılmış bir filamentin mukavemeti üzerindeki etkisi, daha sonra fiber kompozit yapılarda kazara darbeden kaynaklanan sertlik ve mukavemet kaybına neden olur. Yapılan çalışmalar yabancı cisimlerin kompozit yapılar üzerindeki etkileri, yapının gücünü önemli ölçüde azaltan iç hasarlar oluşturabileceğini göstermiştir [22, 23]. Önceki araştırmacıların bir kısmı sorunun ana özelliklerini tanımlamış olsa da, önemli ayrıntılar belirsizliğini korumaktadır. Yassı kompozit plakaların etkisi üzerine bir dizi çalışma yapılmışsa da, uygulamalarda kullanılmalarına rağmen basınçlı kaplar gibi boru şeklindeki geometriler üzerinde nispeten az çalışma yapılmıştır. Hafifliği ve çarpışmaya dayanıklılığı geliştirmek için, geleneksel metalik veya kompozit yapılardan nispeten daha yeni olan metal/kompozit hibrit konfigürasyona artan ilgi olmuştur.

FEA, silindirin gerilim dağılımının nasıl değiştiğini anlamak için yüksek iç basınç altında kompozit silindirlerin analizine iyi bir yaklaşım sağlamaktadır. Şekil 4, girintiden sonra tüp uzunlamasına ekseni boyunca yer değiştirmeyi göstermektedir. İç basınç olmaksızın (sürekli-düz çizgi) borunun uzunlamasına ekseni boyunca yer değiştirmeler her zaman eksi yöndedir. $\mathrm{Bu}$, tüm silindir gövdesinin boş olduğunda daha fazla etkileneceği anlamına gelir. Ancak silindirin uçları, silindir $50 \mathrm{MPa}$ iç basınca sahip olduğunda artı alandadır. Eğrilerin boylamasına yöndeki uzunluklarının karşılaştırılması, $50 \mathrm{MPa}$ iç basınca sahip silindirin daha uzunlamasına deformasyona sahip olduğunu göstermektedir. $\mathrm{Bu}$, darbe yükü altındaki kompozit silindir düşünüldüğünde analitik çözümlere nasıl yaklaşılacağı ve önerileceği önemlidir. Bilindiği gibi, fiber takviyeli kompozitler açısından sıkıştırma mukavemeti gerilim mukavemetinden önemli ölçüde farklıdır. CFRP ve Al eğrilerinin karşılaştırılması, daha önce yapılan çalışmalar Alüminyum boruların sünek davranışı ve kompozitlerin gevrek davranışı nedeniyle, alüminyum borular, kompozit muadillerine göre çok daha iyi yanal çarpışma dayanıklılığı gösterdiğini ortaya koymuştur [24, 25]. Alüminyum tüpün CFRP ile aynı davranışa sahip olduğunu ortaya koymaktadır. Yapılan çalışmada, yer değiştirme birbirine benzer olduğu için alüminyumun CFRP ile aynı şekilde davrandığını göstermektedir. Ancak Al mekanik özelliklerinin CFRP'den oldukça farklı olduğu dikkate alınmalı, bu nedenle kompozit yüksek basınçlı kapların Al gömlekleri yorulma ömrü hesaplamalarına tabi tutulduğunda dikkat edilmelidir.

Al silindirin $50 \mathrm{MPa}$ iç basınç ile iç basınç açısından Von Misses gerilme dağılımı Şekil 6'da verilmiştir. Darbeli deformasyonların meydana geldiği boru ucu ile borunun ortası arasındaki gerilme farkı düşük iç basınçta daha yüksek ve düşük iç basınçta daha yüksektir. Ancak borunun ucu, çarpma tertibatından etkilenen bölgeyle hemen hemen aynı gerilime sahiptir. Tüp tasarlanırken bu dikkatlice düşünülmelidir. 
Genel olarak silindirlerin iç basınç altında tasarlanması sadece gerilimsel mekanik özellikler gerektirir. Şekil 7, silindirin darbe yüklemesi sırasında sıkıştırma ve gerilimin aynı anda gerçekleştiğini göstermektedir. Ortografik malzemelerde çekme ve sıkıştırma mekanik özelliklerinin oldukça farklı olduğu göz önüne alındığında bu şekil, çarpma tertibatının hemen altındaki deformasyonun uzunlamasına yönde bükülme + gerilme, ancak çevresel yönde sıkışmaya dönüştüğünü de ortaya koymaktadır. Çarpma tertibatından silindirin ucuna doğru daha da uzaklaşan gerilim, uzunlamasına ve çevresel yönde aktif hale gelir.

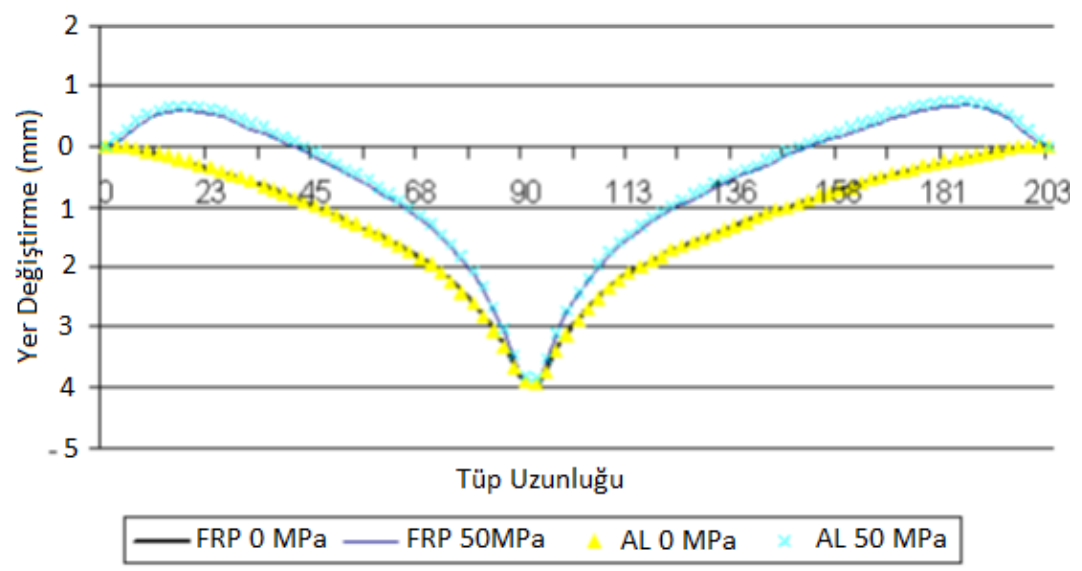

Şekil 5. FRP malzemeleri ve alüminyum üzerinde yer değiştirme

Al

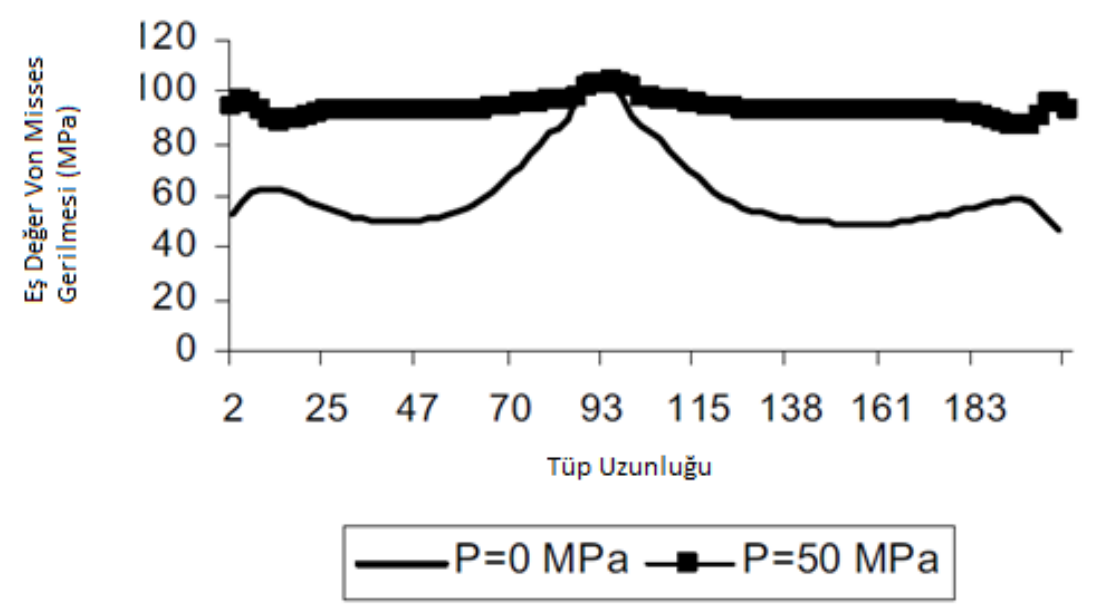

Şekil 6. Alüminyum malzemelerde eşdeğer Von Mises gerilmesi 


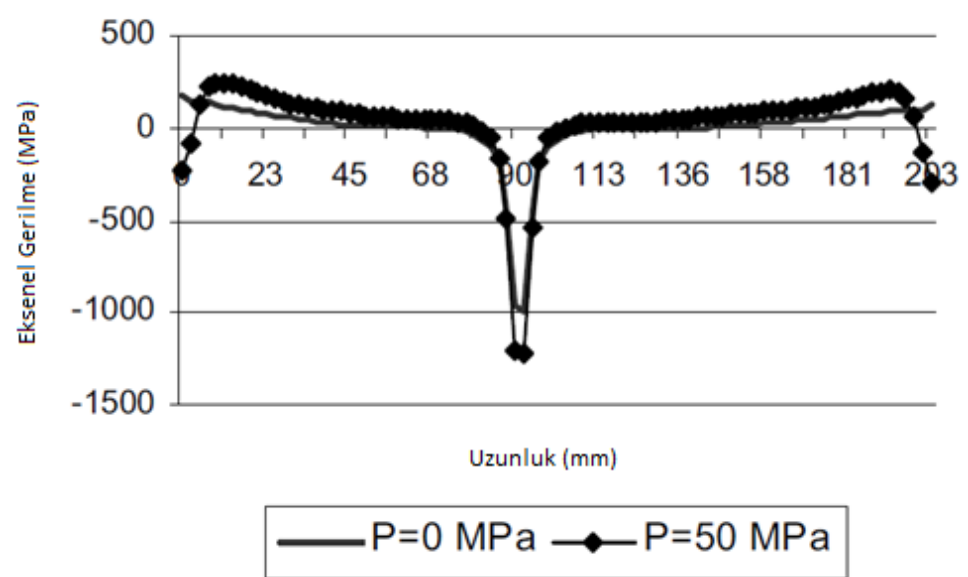

Şekil 7. Basınçsız silindirin boylamasına gerilme dağılımı ve çarpma sonrası $50 \mathrm{MPa}$ iç basınç

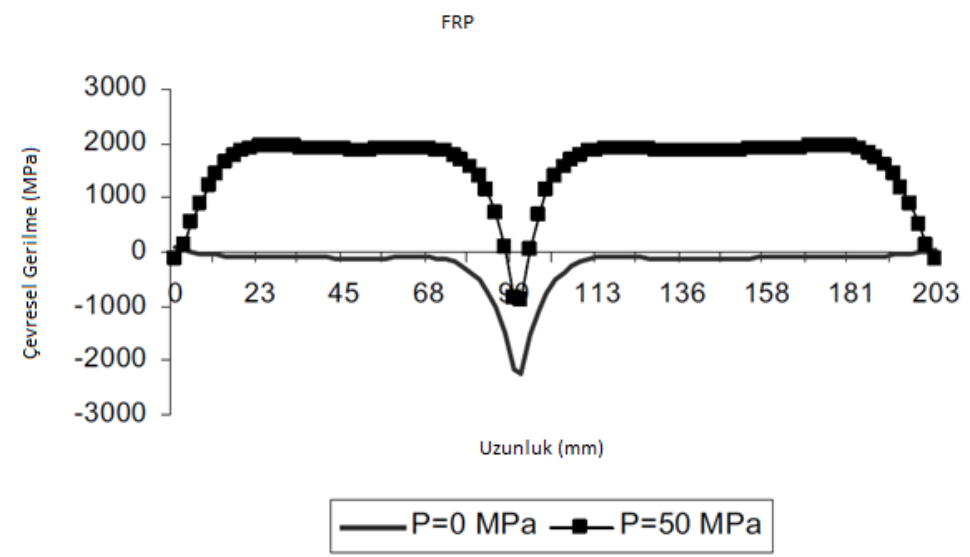

Şekil 8. Uzunlamasına yönde CFRP katmanındaki çevresel gerilmeler

$50 \mathrm{MPa}$ iç basınca sahip ve iç basınçsız CFRP kompozit malzemenin çevresel gerilme dağılımı Şekil 8'de verilmiştir. Kullanılan analiz yazılımı veri tabanında, çarpma tertibatının hızına bağlı olarak bir miktar elyaf kırılmasının meydana geleceği açıklanmıştır. $\mathrm{Bu}$, borunun gerilimin büyük ölçüde yeniden dağılmasına neden olabilir ve Al borunun orta kısmında ciddi plastik deformasyona neden olabilir. Al tüpü yorulma ömrünü uzatmak için otomatik frenlemenin etkisi de etkisiz hale gelebilir.

\section{Sonuç}

Bu çalışmada yüksek iç basınçlı Al + CFRP kompozit silindir üzerindeki darbe yüklemesinin etkisini simüle etmek için bir FE modeli araştırılmıştır. Simülasyon modelinin güvenilirliği, diğer araştırmacılar tarafından yapılan gerçek deney karşılaştırılarak kontrol edilmiştir. Simülasyon sonuçları, genellikle çekme gerilmeleri altında çalışmak üzere tasarlanan ve tasarlanan silindir parçalarının bir kısmının darbe altında sıkıştırma gerilimi altında kalabileceğini ortaya çıkarmıştır. Özellikle hasarlı yüksek basınçlı kapların yorulma ömrünü tahmin etmek için darbeli yükleme altındaki Al + CFRP kompozit silindirin ayrıntılarını anlamak için yapılacak araştırmalar gelecek hedeflerimiz arasındadır. 


\section{Kaynakça}

[1] P. Edwards, V. Kuznetsov, D. Bill, "Hydrogen energy," Philosophical transactions of the royal society a mathematical and engineering sciences, vol. 365 no. 1853, pp. 1043-1056, 2007, doi: 10.1098/rsta.2006.1965

[2] I. Blagojevic, S. Mitic, "Hydrogen as a vehicle fuel," Mobility and vehicle mechanics, vol. 44, no. 2, pp. 37-49, 2018, doi: 10.24874/mvm.2018.44.02.04

[3] Y. Ruf, T. Zorn, P. Neve, P. Andrae, S. Erofeeva, F. Garrison, "Report 3," Study on the use of fuel cells \& hydrogen in the railway environment, 2019.

[4] M. Akhoundzadeh, K. Raahemifar, S. Panchal, E. Samandi, E. Haghi, R. Fraser, M. Fowler, "A conceptualized hydrail powertrain: A case study of the union pearson express route," World electric vehicle journal, vol. 10, pp. 2019 doi: 10.3390/wevj10020032

[5] O. Bethoux, "Hydrogen fuel cell road vehicles and their infrastructure: An option towards an environmentally friendly energy transition," Energies, vol. 13, pp. 1-27, 2020, doi: 10.3390/en13226132

[6] A. Hoffrichter, "Hydrogen as an energy carrier for railway traction," Ph. D. dissertation, Dept. Mech. Eng., University of Birmingham, 2013.

[7] E. Rivard, M. Trudeau, K. Zaghib, "Hydrogen storage for mobility: A review," Materials, vol. 12, pp. 1-22, 2019, doi: 10.3390/ma12121973

[8] N. K. Naik, P. Shrirao, B.C.K. Reddy, "Ballistic impact behaviour of woven fabric composites: Formulation," International journal of impact engineering, vol. 14, no. 9, pp. 1521-1552, 2006, doi: 10.1016/j.ijimpeng.2005.01.004

[9] V. B. C. Tan, T. W. Ching, "Computational simulation of fabric armour subjected to ballistic impacts ,'International journal of impact engineering, vol. 32, no. 11, pp. 1737-1751, 2006, doi: 10.1016/j.ijimpeng.2005.05.006

[10] Y. Duan, M. Keefe, T.A. Bogetti, B. A. Cheeseman, B. Powers, "A numerical investigation of the influence of friction on energy absorption by a high-strength fabric subjected to ballistic impact," International journal of impact engineering, vol. 32, no. 8, pp. 1299-1312, 2006, doi: 10.1016/j.ijimpeng.2004.11.005

[11]Z. Fawaz, K. Behdinan, Y. Xu, "Optimum design of two-component composite armours against highspeed impact," Composite structures, vol. 73, no. 3, pp. 253-262, 2006, doi: 10.1016/j.compstruct.2005.01.037

[12] M. Ubeyli, R. O. Yildirim, B. Ogel, "On the comparison of the ballistic performance of steel and laminated composite armors," Materials \& design, vol. 28, no. 4, pp. 1257-1262, 2007, doi: 10.1016/j.matdes.2005.12.005

[13] V. Lopresto, V. Melito, C. Leone, G. Caprino, "Effect of stitches on the impact behaviour of graphite/epoxy composites," Composites science and technology, vol. 66 no. 2, pp. 206-214, 2006, doi: 10.1016/j.compscitech.2005.04.029

[14] Y. Duan, M. Keefe, T. A. Bogetti, B. Powers, "Finite element modeling of transverse impact on a ballistic fabric," International journal of mechanical sciences, vol. 48, no. 1, pp. 33-43, 2006, doi: 10.1016/j.ijmecsci.2005.09.007

[15] A. G. Mamalis, D. E. Manolakos, M. B. Ioannidis, D. P. Papapostolou, "The static and dynamic axial collapse of CFRP square tubes: Finite element modelling," Composite structures, vol. 74, no. 2 pp. 213-225, 2006, doi: 10.1016/j.compstruct.2005.04.006

[16]M. R. Abdullah, W. J. Cantwell, "The impact resistance of polypropylene-based fibre-metal laminates," Composites science and technology, vol. 66, no. 11, pp. 1682-1693, 2006, doi: 10.1016/j.compscitech.2005.11.008

[17] U. K. Vaidya, S. Pillay, S. Bartus, C. Ulven, D. Grow, B. Mathew, Impact and post-impact vibration response of protective metal foam composite sandwich plates," Materials science and engineering: A, vol. 428, no. 1, pp. 59-65, 2006, doi: 10.1016/j.msea.2006.04.114

[18] G. Gaprino, V. Lopresto, D. Santoro, "Ballistic impact behaviour of stitched graphite/epoxy laminates," Composites science and technology, vol. 67, no. 4, pp. 325-335, 2007, doi: 10.1016/j.compscitech.2006.04.015

[19] MARC User's Guide, Volume A - Theory and user information, MARC analysis research corporation, 2007

[20] MARC user's guide, Volume B-element library, MARC analysis research corporation, pp. 33-43, 2007

[21] S. Wakayama, S. Kobayashi, T. Imai, T. Matsumoto, "Evaluation of burst strength of FW-FRP composite pipes after impact using pitch-based low-modulus carbon fiber," Composites part A: 
Applied science and manufacturing, vol. 37, no. 11, pp. 2002-2010, 2006, doi: 10.1016/j.compositesa.2005.12.010

[22] S. Abrate, "Modelling of impacts on composite structures," Composite structures, vol. 51, no. 2, pp. 129-138, 2001, doi: 10.1016/S0263-8223(00)00138-0

[23] S. Gholizadeh, "A review of impact behaviour in composite materials," International Journal of Mechanical and Production Engineering, vol. 7, no. 3, 2019

[24]L. Shunfeng, X. Guo, L. Qing, S. Guangyong, “On lateral crashworthiness of aluminum/composite hybrid structures, Composite Structures, vol. 245, 2020, doi: 10.1016/j.compstruct.2020.112334

[25] S. Parida, P. Jena, "Design and finite element analysis of thick walled laminated composite pressure vessel," International journal of innovative technology and exploring engineering, vol. 8 no. 10, 2019

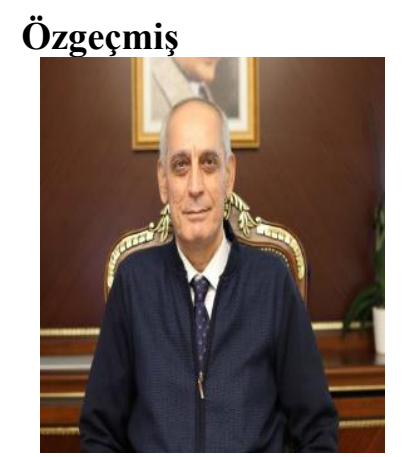

\section{Nihat AKKUŞ}

24 Kasım 1964 yılında doğdu. Lisans eğitimini Marmara Üniversitesi Teknik Eğitim Fakültesi Makine Eğitimi Bölümünde tamamladı. Yüksek Lisans Eğitimini Marmara Üniversitesi Teknik Eğitim Fakültesi Metal Eğitimi Bölümünde tamamladı. Tokyo Büyükşehir Teknoloji Enstitüsünden doktora derecesi almıştır. Halen İstanbul Gedik Üniversitesinde Rektör olarak görev yapmaktadır.

E-Posta: nihat.akkus@ marmara.edu.tr

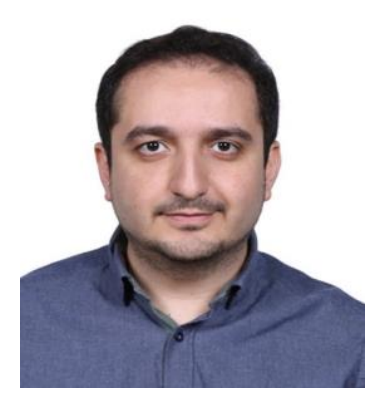

\section{Abdülkadir ÜNAL}

1987 yılında Malatya'da doğdu. Lisans eğitimini Karadeniz Teknik Üniversitesi Makine Mühendisliği Bölümünde tamamladı. Yüksek lisans eğitimini Marmara Üniversitesi Mekatronik Mühendisliği Bölümünde tamamladı. Halen Marmara Üniversitesi Mekatronik Mühendisliği Bölümü Doktora Programında tez aşamasında öğrenimine devam etmekte ve Türkiye Raylı Sistem Araçları AŞ'de çalışmaktadır.

E-Posta: abdulkadir.unal@turasas.gov.tr

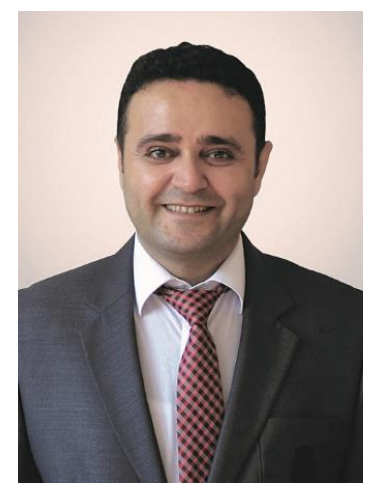

\section{Garip GENÇ}

1977 yılında Hatay'da doğdu. 2001 yılında Marmara Üniversitesi, Teknik Eğitim Fakültesinden Lisans derecesini aldı. Yüksek Lisans ve Doktora derecelerini Fen Bilimleri Enstitüsü, Makine Eğitimi ABD'nda sirasiyla 2004 ve 2008 yıllarında ald1. 2010 yılında Fransa Bourgogne Üniversitesi'nde Doktora Sonrası Araştırmacı olarak bulundu. Halen Marmara Üniversitesi, Mekatronik Mühendisliği Bölümü'nde Doçent olarak görev yapmaktadır. Araştırma alanı, kimyasal ve bitkisel lif takviyeli kompozit malzemelerle ilgilidir.

E-Posta: ggenc@marmara.edu.tr

\section{Beyanlar:}

Bu makalede bilimsel araştırma ve yayın etiğine uyulmuştur.

Tüm yazarların eşit oranda katkısı olmuştur. 